\title{
Cancer, Stress, and Death
}




\section{SLOAN-KETTERING INSTITUTE CANCER SERIES}

Series Editors:

ROBERT A. GOOD, Ph.D., M.D., and STACEY B. DAY, M.D., Ph.D., D.Sc.

Sloan-Kettering Institute for Cancer Research

New York, New York

\section{GASTROINTESTINAL TRACT CANCER}

Edited by Martin Lipkin, M.D., and Robert A. Good, Ph.D., M.D.

CANCER, STRESS, AND DEATH

Edited by Jean Taché, D. Sc., Hans Selye, C.C., M.D., Ph.D., D.Sc., and Stacey B. Day, M.D., Ph.D., D.Sc. 


\title{
Cancer, Stress, and Death
}

\author{
Edited by \\ Jean Taché, D.Sc. \\ International Institute of Stress \\ Pointe-Claire, Quebec, Canada \\ Hans Selye, C.C., M.D., Ph.D., D.Sc. \\ International Institute of Stress \\ Montreal, Quebec, Canada \\ and \\ Stacey B. Day, M.D., Ph.D., D.Sc. \\ Sloan-Kettering Institute for Cancer Research \\ New York, New York
}

PLENUM MEDICAL BOOK COMPANY

New York and London 


\section{Library of Congress Cataloging in Publication Data}

Main entry under title:

Cancer, stress, and death.

(Sloan-Kettering Institute cancer series)

Bibliography: $p$.

Includes index.

1. Cancer - Psychosomatic aspects - Congresses. 2. Cancer - Psychological aspects - Congresses. 3. Stress (Physiology) - Congresses. 4. Stress (Psychology) Congresses. 5. Death - Psychological aspects - Congresses. I. Taché, Jean. II. Selye, Hans, 1907- III. Day, Stacey B. IV. Series: Sloan-Kettering Institute for Cancer Research, New York. Sloan-Kettering Institute cancer series.

(C) 1979 Plenum Publishing Corporation

Softcover reprint of the hardcover 1st edition 1979

227 West 17 th Street, New York, N.Y. 10011

Plenum Medical Book Company is an imprint of Plenum Publishing Corporation

\section{All rights reserved}

No part of this book may be reproduced, stored in a retrieval system, or transmitted, in any form or by any means, electronic, mechanical, photocopying, microfilming, recording, or otherwise, without written permission from the Publisher 
And I would say

I am no doctor

I am a physician

I am your pilot

Come to guide your ship home to its last dock.

—From the "Last Dock" by Stacey B. Day 


\section{Participants}

Pierre Band, M.D.

Director of Clinical Research

Montreal Cancer Institute

Montreal, Quebec H2L 4M1, Canada

Stephen Nye Barton, M.D., Ph.D.

Assistant Professor of Public Health

The University of Alabama in Birmingham

Birmingham, Alabama 35294

President, American Rural Health Association

Birmingham, Alabama 35205

Debbie Bowles, R.N., B.S.N., P.N.P.

St. Jude Children's Research Hospital

Memphis, Tennessee 38101

Aaron Bendich, Ph.D.

Member and Professor

Sloan-Kettering Institute for Cancer Research

New York, New York 10021

G.M. Brown, M.D., Ph.D.

Chairman, Department of Neurosciences

McMaster University

Hamilton, Ontario L8S 4J9, Canada 
viii

Eric J. Cassell, M.D., F.A.C.P.

Clinical Professor, Department of Public Health

The New York Hospital

Cornell University Medical College

New York, New York 10021

Barbara G. Cox, B.S.

Executive Editor and Manager

Biomedical Publications, Ross Laboratories

Columbus, Ohio 43216

Stacey B. Day, M.D., Ph.D., D.Sc.

Member and Professor

Sloan-Kettering Institute for Cancer Research

New York, New York 10021

Joel Elkes, M.D.

Distinguished Service Professor

Johns Hopkins University

Baltimore, Maryland 21218

Visiting Professor

McMaster University

Hamilton, Ontario L8S 4J9, Canada

Robert Fulton, Ph.D.

Professor of Sociology and Director

Center for Death Education and Research

University of Minnesota

Minneapolis, Minnesota 55455

Irwin H. Krakoff, M.D.

Professor and Director

Vermont Regional Cancer Center

University of Vermont

Burlington, Vermont 05401 
Terence E. Lear, F.R.C.P.I., D.P.M., F.R.C.Psych.

Physician and Consultant Psychiatrist

St. Crispin Hospital

Northampton, England NN2 6JF

Martin G. Lewis, M.D., M.R.C.(Path.)

Chairman, Department of Pathology

Georgetown University School of Medicine and Dentistry

Washington D.C. 20007

Wolfgang Luthe, M.D.

Scientific Director, Oskar Vogt Institute

Visiting Professor

Kyūshū University

Fukuoka, Japan

Balfour Mount, M.D., F.R.C.S.(C)

Director, Palliative Care Unit

Royal Victoria Hospital

McGill University

Montreal, Quebec H3A 1A1, Canada

Janet Schyving Payne, A.C.S.W.

St. Jude Children's Research Hospital

Memphis, Tennessee 38101

Paul J. Rosch, A.B., M.A., M.D., F.A.C.P.

Chairman

American Institute of Stress

301 Park Avenue

New York, New York 10022

Milagros Salas, Ph.D.

Research Fellow

Montreal Cancer Institute

Montreal, Quebec H2L 4M1, Canada 
Hans Selye, C.C., M.D., Ph.D., D.Sc.

President, International Institute of Stress

University of Montreal

Montreal, Quebec H3C 3J7, Canada

Jean Taché, D.Sc.

Director, Center for Applied Stress Studies

Pointe-Claire, Quebec H9S 4J7, Canada

President, The Stress Corporation

8100 Paseo del Ocaso

La Jolla, California 92037

Mary L. S. Vachon, R.N., M.A.

Community Resources Section

Clarke Institute of Psychiatry

Toronto, Ontario M5T 1R8, Canada

Edmund Yunis, M.D., Ph.D.

Professor of Pathology

Harvard Medical School and Chief, Division of Immunogenetics

Sidney Farber Cancer Institute

Boston, Massachusetts 02115 


\section{Foreword}

When I delivered the keynote address at our joint 1977 symposium on Cancer, Stress, and Death in Montreal, I took great pride in announcing my unique qualification for this singular honor-I had survived a normally fatal cancer, a histiocytic reticulosarcoma that had developed under the skin of my thigh several years previously.

Faced with the physical and emotional realities of this situation, I refused to retreat from life in desperation. I immediately underwent surgery and cobalt therapy, but insisted on knowing my chances for a lasting recovery, which at that time seemed far from encouraging. Although I knew it would take tremendous self-discipline, I was determined to continue living and working without worrying about the outcome.

I suppressed any thoughts of my ostensibly imminent death, but rewrote my will, including in it several suggestions for the continuation of my work by my colleagues. Having taken care of that business, I promptly forced myself to disregard the whole calamity. I immersed myself in my work-and I survived! But, of course, this was not my only reason for my feelings of pride and accomplishment.

I have since succeeded in creating the International Institute of Stress, and one of its first major symposiums was specifically arranged to highlight the interrelation between stress, cancer, and death. The Memorial Sloan-Kettering Cancer Center added prestige to our venture by cosponsoring this event and ensuring the 
participation of many leading experts, whose work on stress and cancer is well represented in this volume.

We know very little about the possible relationship between stress and cancer, but no one can ever doubt that stress enters into every kind of human activity and that it is responsible for many of today's diseases of adaptation. Indeed, under general stress, it is always the weakest link in the chain-the weakest part of the human mechanism-that breaks down first. There is no reason, therefore, to exclude stress from being a critical factor in the development of cancer, which in itself is also a major source of stress in these patients. I think it would not be very difficult to understand that a person who is about to die of cancer is under stress, at least in the original sense of the word-what we now prefer to call distress.

Several years ago, I personally did an experiment which amused me very much. I implanted chemically inert pyrex rings of a certain shape under the skin of some rats, and they produced a sarcoma in $100 \%$ of these animals. I still do not know how this came about, but I suspect the pyrex rings must have been highly irritating. Rather surprisingly, broken pieces of pyrex failed to duplicate this effect. We had to use pyrex rings of specific dimensions because any other shape was ineffective. This provides clear-cut evidence that local stress (discussed in Chapter 2) is carcinogenic only under certain conditions.

So the possibilities seem limitless, especially when one considers the relationship between stress, altered emotional states, and cancer. Perhaps, as Paul Rosch of New York has suggested, cancer might even be an attempt by the human organism to regenerate tissues and organs and even limbs, as lower animals are able to do spontaneously. Going further, one might say that "the ultimate health of the organism, like that of society, appears to depend on how well or appropriately its constituent units communicate with one another." As I said in my book Stress without Distress, "the indispensability of this disciplined, orderly mutual cooperation is best illustrated by its opposite-the development of a cancer, whose most characteristic feature is that it cares only for itself."

I believe that new findings in cancer research will eventually provide many answers to mankind's everyday psychosocial prob- 
lems. I do know that my own experience with the disease helped me to develop a very satisfactory code of conduct, and it is my hope that the various contributions to this book will take us a little further toward a more coherent theory on cancer, one that will correlate the vast multitude of findings in the scientific literature on stress, cancer, and death.

Hans Selye, C.C., M.D., Ph.D., D.Sc. President, International Institute of Stress University of Montreal Montreal, Quebec, Canada 


\section{Preface}

Oliver Wendell Holmes, speaking of the joy of life, remarked of Malebranche that if God held in one hand truth and in the other the pursuit of truth, the grand gentleman would say, "Lord, the truth is for Thee alone; give me the pursuit." It is the pursuit to its ulterior spiritual end-to death-that most thinking people, I believe, would turn, and it is to this end that the integrated views in this book are directed.

The ideas and concepts presented here originated with colleagues in intellectually diverse disciplines. The matters of which they speak and the research which they relate bridge a variety of fields of learning and should contribute to a broader and more sensitive understanding of cancer, stress, and death. Their ideas permit an elucidation and analysis of the consequences of those fields and of the different multicentric cultures that make up our rapidly shrinking world.

If we are not able to master the induction and process of ideas in these fields precisely (for the dimensions are too wide), our efforts at integration of interdisciplinary learning are at least beginning. There is more and more interest in and felicity for work in the nonworld of spaces that have existed between disciplines. Slowly such nonworld spaces, through the efforts of those few who are laboring in between disciplines, are closing. Note is being taken of their efforts to synthesize professional knowledge of what has been virtually left as a serious gap in the backdrop of our learning. This book presents evidence rather than testimony to those results 
pioneered in new dimensions of both contributory and participatory education.

Interest generated by this colloquium should therefore emphasize discussions and ideas from papers contributed by those who have labored at what might appropriately be called the grassroots level of the intellectual constructs of our society. Here, bridging gaps, cementing disciplines, and forging communions from these nonworlds, many talents have formed the concepts that are increasingly regarded as interdisciplinary communications and learning. These constructs, which are secured from the spaces of the nonworlds, form the new matrices of contemporary advances in scholarship and education.

Out of this testing work has come the thought-provoking areas of biosocial development, the sociological aspects of medicine inherent in such viewpoints as the patient-as-a-person, an understanding of interacting cultures, including science (for science is very much a culture), and important new syntheses and visions many of which are intrinsic in the observations on cancer, stress, and death presented here.

The Montreal colloquium was of value in encouraging and setting forth Malebranche's pursuit of truth in the will of the integrated philosophy just described. Perhaps Oliver Wendell Holmes himself might approve of the convening of tasks evident in studies of psychophysiology of stress, concepts of the brain as a self-regulating organ, the value and need of death education, and fascinating strengths beyond prospect, of cultural anthropology as an analytical instrument for evaluation of cultural transformations, sociological problems, and paradoxes and apparent incoherencies in the diversity of cultures within which all must live, and to which all must respond. Wise utilization and keen interpretation, using interdisciplinary analysis reasonably, promise a more sensitive appreciation of life forces that beget so many of our shared problems, including those of cancer, stress, and death.

This volume, and the themes it evokes, evolved from a cooperative, international, interdisciplinary, educational exchange that met under the sponsorship of the Sloan-Kettering Institute for Cancer Research (Biosciences Communication and Education), and the institute directed by Hans Selye, devoted to the research and 
elucidation of stress-the International Institute of Stress in Montreal, Canada.

It is by such socially oriented health research programs that more accessible, more profoundly human, and more participatory public attention can be brought to bear in fields of health education that benefit society, and that are of critical concern to patients as well as to physicians.

Stacey B. Day 


\section{Contents}

Foreword

$x i$

Hans Selye

Introduction: Stress as a Cause of Disease

1

Jean Taché

1. Stress, Cancer, and the Mind

Hans Selye

2. The Possible Effects of Emotional Stress on Cancer

Mediated through the Immune System

Martin G. Lewis and Terence M. Phillips

3. Stress, Hormone Responses, and Cancer

G. M. Brown, J. Seggie, and P. Ettigi

4. The Biological Axis of Senescence, Stress, and Aging as Construct for Cancer, Disease, and Death

Stacey B. Day and O. Garzon Duhov

5. Advanced Malignant Disease and the Person Under Stress

Balfour Mount 
6. The Homeostatic Significance of the Death-Life Cycle Dynamics in Mental Functions Wolfgang Luthe

7. The Cancer Patient as Educator and Counselor Barbara G. Cox

8. Anticipatory Grief, Stress, and the Surrogate Griever 87 Robert Fulton

9 Bereavement: Including Some Iatrogenic Aspects of Grief

Terence E. Lear

10. Physical Deterioriation in Patients with Advanced Cancer

Irwin H. Krakoff

11. Summary Comments Joel Elkes

12. Telling the Truth to the Dying Patient Eric J. Cassell

13. The Use of Group Meetings with Cancer Patients and Their Families Mary L. S. Vachon, W. Alan Lyall, Joy Rogers, Anton Formo, Karen Freedman, Jeanette Cochrane, and Stanley J. J. Freeman

14. Stress, Cancer, Death-A Pediatric Perspective Debbie Bowles and Janet Schyving Payne

15 Rural Cancer Death Stephen Nye Barton, David W. Coombs, and John P. Zakanycz

16. Discussion 
CONTENTS

17. Stress and Cancer: A Disease of Adaptation?

Paul J. Rosch

18. Death Not the Mysterium Tremendum: A Summary Overview

Stacey B. Day

Recommended Reading

Index 